\title{
Group Dynamics and Behaviour
}

\author{
Hüseyin Gençer \\ Maritime Higher Vocational School, Piri Reis University, Istanbul, Turkey
}

Copyright@2019 by authors, all rights reserved. Authors agree that this article remains permanently open access under the terms of the Creative Commons Attribution License 4.0 International License

\begin{abstract}
Individuals are always in interaction with other individuals outside, as well as in the group and with the group itself. This is why the social sciences emphasize the importance of group dynamics. After the 1990's, with the globalization, digitalization, changing political systems, goal or result-oriented approaches in many western countries, new items such as cross cultural differences and impacts, migration, social status and identity, demographic diversities, leadership, job performance, motivation, dynamics in sport teams, organizational citizenship behavior (OCB), ethics, healthcare have been investigated in the studies on the groups and group dynamics. This study provides general information about the studies on the groups and group dynamics.
\end{abstract}

Keywords Groups, Group Dynamics, Intergroup Dynamics

\section{Introduction}

Individuals are always in interaction with other individuals outside, as well as in the group and with the group itself. This is why the social sciences emphasize the importance of group dynamics. In this study, group dynamics were reviewed within the scope of the most accepted concepts and theories in the literature, and international studies done until 2013. The structures and formations of the groups were not examined in detail in order not to confuse and deviate from the target subject. Essentially, all generally accepted approaches about group structure and formation are old theories. Namely, no new approaches about the group structure and formation have emerged in the recent years.

This study was structured according to the subjects in recent researches and basic concepts in the literature. In the first chapter of the study, groups and history of the group researches were shortly explained, and group dynamics were discussed. Additionally, influence of the group and group norms on the individual, and relations between group and changes of the individual's attitude were covered.

In the second chapter, intergroup dynamics were mentioned very briefly and causes of intergroup conflict were discussed.

Third chapter of the study expresses the benefits of the groups to organizations that have also been supported by recent studies in the literature.

Final chapter summarizes the concepts and subjects explained in the previous chapters within the light of new trends in group dynamics, and concludes the study with some suggestions.

\section{Groups and Group Dynamics}

A Group is a formation of at least two people who come together in a given purpose, communicate with each other, affect each other and are dependent on each other. To be a group, a crowd should have common objectives and norms, but also they should be feeling themselves as a group[1]. Groups that are worked on by sociologists, social and organizational psychologists are mostly the small groups. Like older studies, recent studies in the literature have also been conducted on small groups.

What can be the reasons for examining small groups? We spend a significant part of our lives in small groups such as family, group of friends, work groups etc. Small groups reflect society as a whole. Besides, the identities of individuals and their effects reveal better in small groups. Moreover, it is also easier and more appropriate to practice the small groups in a laboratory environment.

Kurt Lewin stated that groups are dynamic and powerful beings which have power to influence individuals and communities. The concept "group dynamics" refers to changes that may occur in any part of the group and bring out actions and reactions in the group structure that affects group members. In order to understand the groups, their dynamics need to be analyzed. Lewin made significant contributions to studies of group dynamics - attitudes and behaviors within the small groups. In his group dynamics theory, he describes groups as open and complex systems, and characterize as internal and external forces that affect 
the behavior of the group[2]. Contemporarily, according to the needs and developments, new items are participating in these forces. Nevertheless, recent studies also investigate interaction of these forces with themselves and each other.

\subsection{Development of Groups Related Studies}

First studies about groups began in the 1850's. These studies mostly focused on the concept of "group spirit" that maintained its importance until 1930's. However, since "group spirit" was being considered as a feature of metaphysic, it did not seem like a proper subject of scientific research. Floyd Allport (1924) rejected the concept of "group spirit" and expressed group as an alteration and acceleration of individual's behavior because of the presence of others. Likewise, previous studies of Triplett (1897), Moede (1920) were also supporting Allport's approach and revealed that the behavior of an individual differs when he is alone than within the group [3].

With the establishment of group formation norms experimented by Sherif (1936), "group" has been accepted as a concrete fact. After that, since the late 1930's, the guiding effect of Kurt Lewin about group studies has started. After the 1960 's, it can be seen that the studies have scattered and covered a wide range of groups, and application has gained much more importance [4]. Studies on groups have been made in the fields of industrial and organizational psychology, education, mental health, military and so on. Studies made in the laboratory were applied in all these areas.

After the 1990's, with the globalization, digitalization, changing political systems, goal or result-oriented approaches in many western countries, new items such as cross cultural differences and impacts, migration, social status and identity, demographic diversities, leadership, job performance, motivation, dynamics in sport teams, organizational citizenship behavior (OCB), ethics, healthcare have been investigated in the studies on the groups and group dynamics. Moreover, groups consisting of virtual (online) environment is noteworthy in recent years, especially in international organizations. Considering the business meetings via tele-conferences, carrying out the job only with Emails, it is not clear who is within the group or who is out. There are some work groups in international companies consist of a dozen people who do not see each other for many years. Some researchers have already started to examine these entities and their effects on group dynamics [5].

\subsection{Group Norms and Group's Normative Effect}

Group norms can be defined as rules that specify what kind of behavior is appropriate or unwanted within the group. These rules provide guidance for the behavior of group members and are adopted by them. Members who want to stay in the group must adapt to the rules, otherwise they would be removed from the group. Norms are the components of a group that hold the members together, supervise them, and make a strong and lasting group. Formation of the norms is performed by a leader or any member. However, continuity of the norms is provided by the group and it is difficult to change them. After the adaptation, norms are seen as means of social pressure. In case of deviation from the norms, members are made to feel this in a variety of ways [6].

According to researches, an individual behaves in a group differently than being alone. Considering the norms and hierarchy in groups, members who observe the rules in the group are usually called as middle level ones. These individuals mostly follow the rules even when they are alone in order to secure their places in the group [7].

There are also members in the group who are in the lower levels. Those observe the rules only within the group. Such a behavior is materialized not by adopting but by submission. This kind of members believe that their group is better than other groups in the environment and show the behavior of keeping the rules only not to be removed from the group. On the other hand, those in the upper levels of group remained tied to the rules in the beginning. These members liked and adopted for a period of time, and gain high esteem within the group. After becoming leader they may violate the group rules to some extent [8].

In recent years, the effect of group norms and their relations with other group activities and values such as justice, ethics, knowledge transfering, performance, innovation etc. have often been investigated in the literature [9,10,11].

Kivlighan Jr. and Cole [12] examined the relationship between absenteeism and commitment in terms of group norms. As expected, this study exhibited that employees who are more committed to the group are more influenced by the group's absences norms than are employees less committed to the group. Generally, it can be said that commitment and compliance with group norms have a positive relationship. But for the norms of other counterproductive behaviors such as turnover, substance use, ineffective performance, accidents etc. the results might be different.

Tauber and Sassenberg [13] viewed a football team over a season in order to examine the impact of identification to group norms. In their study, they found that strongly identified group members are more likely to deviate from group norms in some situations. According to this study, members who show stronger identification are more concerned with success and favor of the group. Attitudes of those strongly identified members deviate from the group norms when they perceive that group norms may be harmful for the group. Those members raise their individual goals by ignoring the group goals and show better performance with their ambitions. This 
mostly increases group's performance too. On the other hand, weakly identified players adhered to potentially harmful group norms by adjusting their individual goals to unambitious group goals. This may reduce the performance of the group and strongly identified members tend to leave the team consequently. This study has shown that a group also needs dissidents, who deviate from the group norms, since those uplift the group with their individual high performance. Additionally, non-compliance with the group norms may sometimes lead to better and more effective results.

\subsection{Roles in the Group}

The Role refers to the attitude and beahavior of individuals in accordance with the expectations from each other. In other words, "roles are patterns of behaviors in any social unit"[6]. The attitudes and behaviors form the role identity of individuals. Roles are shaped and developed according to the individual's or group's needs and preferences. In the organizational psychology, roles have been examined according to the general tasks and behaviors within the group. Nowadays, the role is represented by identity by taking into account the impact of social life outside of the group as well. Likewise recent studies mostly focus on the concept of identity that also includes personal characteristics of individual and influences his/her social status outside of the group.

\subsection{Adherence to the Group}

One of the most important features that identifies the structure of the group is members' adherences to the group. Adherence can be described as the desire of the individual to be a member of the group. In a group in which the adherence is high, the group members are pleased with each other and motivated to stay in the group. Moreover, individuals in such groups adopt norms and goals easily, and help each other to achieve the goals. On the other hand, in the groups consisting of members who are not connected to each other, the situation is completely the opposite. To put it clear, adherence to the group is a positive fact. Groups with high adherence do not escape from work, work well together, are more efficient and productive, and in such groups turnover is low and intra-group confidence and motivation of the members is high[14,15]. Moreover, decision making in such groups is of good quality, stronger and more efficient than in other groups. However, there might emerge some problems in relation with other groups [16].

\subsection{The Effect of the Group on Individual's Attitude}

Group has a role in the direction of empowering or changing the attitude of individual. If the individual attitude is compatible with the group norms, this reinforces the attitude. If the individual's attitude is contrary to the group norms, there begins pressure to change this attitude. Moreover, if the group norms are composed from the debate of members, complying with these norms would be more powerful [7]. Many researches (studies of Kelly, Woodruff, Thibaut and Lewin) in the classical social psychology literature have already supported those judgements [3].

Dreu et al.[17] investigated creativity and innovation in the groups. As many earlier studies revealed, their study also showed that individuals with high epistemic motivation are more creative than individuals with low epistemic motivation are. When the members with high epistemic motivation increase within the group, the performance of the group in terms of creativity would also increase. Their study demonstrated that the increase of the average level of epistemic motivation and creativity in the group, would also raise the mental (cognitive) motivation and creativity of the individuals.

Groups can sometimes help those members who have counter-productive behaviors or run against the organizational goals, by reducing or completely eliminating the counterproductive behaviors [8]. This can be seen as a positive impact of the group's effect. On the other hand, a hard-working member in a low-effort group might feel himself as an offset due to possible pressure on him and consequently, either decreases his work effort or leaves the group.

\subsection{The Effect of the Group on the Efficiency of the Individual}

Researches have shown that a group may have a positive or negative effect on the efficiency of its members. According to many social psychologists, the presence of others increases the motivation and action level of the individual. In that case dominant dispositions of the individual play an important role. This means that if the individual has a dominant tendency to make mistakes, his mistakes would increase; if the individual has a dominant tendency to make the right, his deal of doing the right jobs increases [3]. Several studies have shown that the total productivity of the group is greater than the sum of the productivity of its members. This is usually called as "sinergy effect" [18]. Some recent studies about the effect of group on the efficiency and productivity of its members will be mentioned in the sub-title of "The Importance of Groups for Organizations”.

It is also possible that individuals will make less effort while they are in the group than equal to their normal individual effort. This is called as "social loafing". In that case, individual acts quite free in the group. Hence, this is also known as "free riding". For example, in a group of 10 members, given that each member's contribution is 1 , group's output is expected to be greater than 10. But in social loafing occurrences, the output of the group might be 9 or even less. Especially, as the number of group members increases, the proportion of contribution of some members 
decreases [1]. Many researchers claim that social loafing usually occurs in the individualistic cultures where personal achievement and rewarding are important. On the other hand, one may argue that individuals would work harder if they know that they would be rewarded. Therefore, it would be wrong to look at social loafing from only one approach of the culture. Other factors such as job ethic, organizational norms and values, social preferences may also play an important role in the occurence of social loafing.

Kalay and Oğrak[19] analyzed social loafing tendency and behaviors of those engage in social loafing in the groups. The authors stated that some group members, who engage in social loafing, treat their co-workers and supervisors politely, and try to look like helping them. Such situations make it difficult to determine the less effort of those individuals, but still have a negative impact on the group's total performance. For that purpose, groups will be concentrating on the active monitoring in the future.

\subsection{Other Factors in Group Dynamics}

Features, knowledge, skills, communication abilities and behaviors of the members determine who will be the leader in the group. According to the changes of group's desired goals, contingency of being leader of the members also varies. Leadership within the group occurs depending on the interactions of the group, group's goals and characters of the members. According to general leadership approaches, a person who has leadership qualities, regardless in which group, would be the leader [20]. In the literature, situational leadership approach is prominent and mostly highlighted in group dynamics. According to this approach, the environment or group's atmosphere creates the leader within the group. In other words, the leader arises in accordance with needs and features of the group. This approach is similar to the Fiedler's Contingency Theory. In this leadership theory, leader strengthens relationships and adherence between group members, as well as enables the job done in a best way. Consequently, the leader raises his/her reputation and efficiency in the group [1].

Studies have shown that leaders, who are more suited to the group norms, give their group members more confidence. Additionally, leader's fairness is accepted and understood by the group members more effectively. Leaders who do not meet the group's norms have less control and effectiveness over the group. In such cases, some members are getting more close to each other. Nevertheless, such cases mostly affect relationships of the members negatively [21].

An interesting study made by Kivlighan and Miles [22] showed that members are more satisfied in the groups where a second leader (co-leader) exists than the groups with an individual leader. The commitment among members is also stronger in such groups. So in the future, approaches of shared leadership might be more important rather than one person's leadership.

Another topic investigated in recent years and has significant impact on group dynamics is cross-cultural influences[23]. Considering the steadily increased mobility of people, countries, cities, organizations and consequently the groups will be more heterogeneous in the future. Thus, cultural elements will be more examined in group dynamics. For that matter, the importance of the effect of national culture will be decreasing and mixed-multicultural groups will come to the fore rather than pure groups.

As mentioned in the first chapter, online aggregation is now the trend in the business environment, in many public services and even in education. Face to face communication or relationships have always been one of the most effective and valid factors in group dynamics. Nevertheless, increasing technology, changing requirements, time constraints have led people to online communication. Therefore, a lot of new elements and approaches will arise that may affect group dynamics especially in the groups coming from online together [5].

With the increasing importance of self-interest, ambition and gaining, people have also changed their point of view against the groups. That is to say people began to look from a more hedonistic point of view. This has led the researchers to examine the group dynamics in terms of game theory. Chen and $\mathrm{Li}$ [24] studied individuals' behaviors in the groups by considering group identity and social preferences. This study was conducted in laboratory and it has revealed that group members keep the social welfare maximized when they are matched with another group member. They also show more charity when they have a higher punishment. When there is lower payoff, the members that are matched with each other show less jealousy. In contrast, members tend to keep the losses at a minimum level when they are not matched with another group member.

Social identity and its effects have also been studied within the group dynamics. However, those are mostly discussed in intergroup dynamics.

\section{Intergroup Dynamics}

We encounter a lot of intergroup interactions in every moment of life. Political relations between countries, mutual relations of fans of sport teams, communication with other departments in the companies can be examples for the intergroup behaviors in our everyday lives.

While people have social relationships with the individuals from many different social groups, they also may engage in interpersonal behaviors with those invidiuals. Eventhough advancing personal relationships, those people may engage in intergroup behaviors due to being a supporter of different sport teams or political parties. 
There are different theories explaining group dynamics but only two most widely accepted theories - Intergroup Conflict and Social Identity - will be discussed here.

\subsection{Intergroup Conflict}

The most famous theory in intergroup conflicts was put forward by Sherif. According to him, one of the main causes of the conflict is the struggle to achieve limited sources. In other words, the quality of the relations between two groups depends on whether the conflict of interests exists. In a context where resources are limited, competition leads to biases among the groups. As a first result of the conflict between groups, the communication channels of the groups are impaired. After that conflicting groups throw the opponent group in a negative pattern[8].

Some researchers examined the relation between personal characteristics and intergroup dynamics. It has been found that individual differences in terms of cognitive activities also cause intergroup biases and wrong perception, and consequently intergroup conflict[25].

Regardless of how it reveals, intergroup conflicts lead to deviations in achieving the group goals and affects groups's performance negatively, especially in the beginning of occurrence of the conflicts. Despite the negative impacts, there are also positive impacts of intergroup conflicts such as increasing the solidarity and unity in the groups themselves. Especially, organizations gain a lot of experiences through intergroup conflicts. Intergroup conflicts can be hindered by diagnosing and abolishing the causes of the conflict, increasing the communication among groups and individuals in these groups, and especially eliminating the trend of win/loss.

McPherson and Parks made a study which have had gratifying results. According to their findings, groups have stronger tendency to eliminate the conflicts with other groups than individuals do, and at the same time, are more likely faster than the individuals in eliminating the conflicts[26]. This can be seen as another benefit of operating with and within the groups.

\subsection{Social Identity}

Individuals define and evaluate themselves by taking into account the social groups which they belong to. In other words, individuals identify and categorize themselves according to their social groups (as we and they, or in-group and out-group) so that their social identities arise. Other groups in the environment provide a basis in the assessment of the position of individual. Namely, individuals compare their own groups to other groups and mostly favor their own groups[7].

Many studies have shown that individuals who have similar social identities cooperate more comfortable and easily. Moreover, efficiency of cooperation of the members in the same group also changes according to the degree of social ties, mostly directly proportional.

Referring to the study done in the laboratory by Chen and $\mathrm{Li}[24]$ which was mentioned in the previous pages; when individuals from different groups are matched with an in-group member (who is from a different work group but from a similar social group) are more likely to show more charity when they have a higher payoff. Conversely, those individuals show less jealousy when they have a lower payoff. This study has also exhibited that individuals tend to reward ingroup match for good behavior, compared to an outgroup match. On the other hand, they are less likely to punish an ingroup match for misbehavior. Furthermore, the individuals pay more attention on payoffs rather than rewards.

\section{The Importance of Groups for Organizations}

Groups are part of the organizations and cannot be excluded because the best way to overcome problems is to work within groups. As many studies have shown, it is possible to increase the efficiency of production by working in groups. Proficiency of problem solving and process improvement is greater in groups than separate individuals. The aim of working in groups is to increase the contribution of human resources further to the organization. If the right conditions and sinergy are created to achieve important and challenging tasks, a significant difference between group's - and individual's effort emerge accordingly; individuals work more effectively within groups. This is one of the key elements to provide a competitive advantage and being long-lasting organization.

Some researchers claim that group formation is extremely important in the development of attitudes and behaviors of individuals. For example, helping is a spontaneous behavior that may ocur in a group. The formation of a group is a critical element in facilitating such behaviors [27]. According to the study of Yee and Dyne[28], helping behavior is higher in groups in which the cohesion between members is strong, task confusion is low and strong institutional norms exist.

In a similar study carried out by Kidwell and Valentine[29], it has been proved that groups have positive characteristics such us developing the attitude of helping each other, providing cohesion between individuals and support for peer leadership, facilitating interaction between individuals, so that they affect job satisfaction and performance of employees in a positive way.

Kleingeld et al.[30] examined the effect of goal setting on group performance and found that group goals have a robust effect on group performance in the organizations. Individual goals may also have a positive contribution on group performance. Nevertheless, goals embraced by a lot 
of individuals have a better effect on group performance.

In brief, benefits of the groups to organizations are as follows $[31,32,33]$ :

- $\quad$ alleviating the workload

- developing the creativity

- eliminating the weakness of supervisor

- creating communication channels for individuals

- helping employees to feel better emotionally

- providing an effective decision-making in case the decision-making process operated accurately

- allowing individuals to control each other which may be more effective than the control of supervisors

- $\quad$ ensuring job satisfaction and stability

- reducing problems especially in large-scale organizations.

\section{Conclusions and Recommendations}

In the organizations, beside the importance of characteristics and management of the individuals, formation of the groups by those individuals, and their interactions within the groups are also crucial. Since this is very well known, researches have being done on this topic for decades. First studies sought to answer the question of how an individual affected from being in a group. Afterwards researches have been focused on group dynamics - interactions between group and its members which are also being studied today. As it can be understood from the theories and researches in the literature, group dynamics was examined first in the social psychology. Later, the importance of the groups in organizations have been comprehended and started to be investigated in organizational psychology. Nevertheless almost all the theories or infrastructural studies still used in organizational psychology have been taken from social psychology. Likewise, most of the researchers studying the group dynamics have the origin of psychology science. The biggest reason of moving towards the organizational psychology is probably the effect of high return money in that area.

As seen in the first chapter of this study, subjects examined in recent group dynamics studies are mostly similar to the past researches. The main difference is some topics - such as characteristics of individuals and groups are being examined in more detail. Moreover, an important fact stands out; in an environment where the competitiveness is imposed, studies are progressing in the direction of how to achieve the maximum benefit and best results. In that respect, some subjects brought by competitiveness such as leadership, cross-cultural interaction and online/virtual aggregation are getting more important in group dynamics. Sport industry is and will be attracting more attention since it always grows and attracts money. At the same time, it is simple and visible to measure the performance and results in sport teams. Thus, group dynamics might be studied more in sports. Unfortunately, it must be highlighted that a group consisted of individuals is being considered like a machine and this may cause the disregard of some human values.

The main reason of the intergroup conflict is also the competitive environment; the greater competition, the greater conflict or hostility. Conflict leads to prejudice among the groups and this abandons the communication between the groups. In order to make positive intergroup perceptions and behaviors, co-operation should be encouraged among the groups.

As mentioned in the third chapter, groups contribute positively to organizations such as creating collaboration among employees, providing an effective communication, increasing job satisfaction and motivation, and gaining competitive advantage. On the other hand, intergroup conflict may cause negative effects such as decrease in productivity and power of competition. To prevent or minimize the occurrence of adverse effects, organizations should be aware of the functioning of the groups, group dynamics, characteristics of the individuals, and use correct methods and techniques.

\section{REFERENCES}

[1] R. Kreitner, A. Kinicki. Organizational Behavior, 9th edition, McGraw-Hill, New York, 2010.

[2] T. S. O’Connell, B. Cuthbertson. Group Dynamics in Recreation and Leisure, Human Kinetics, Illinois, 2009.

[3] Ç. Kağıtçıbaşı. Sosyal Psikolojiye Giriş, Duran Ofset Matbaaclık Sanayii A.Ş., Istanbul, 205-209, 1977.

[4] D. Grandberg, G. Sarup, Social Judgement and Intergroup Relations: Essays in Honor of Muzafer Sherif, Springer-Verlag, New York, 1992.

[5] R. Wageman, H. Gardner, M. Mortensen. The changing ecology of teams: New directions for teams research, Journal of Organizational Behavior, 33, 301-315, 2012.

[6] H. Can, Ö. Aşan, E. M. Aydın. Örgütsel Davranış, Yaylacık, Istanbul, 2006.

[7] N. Bilgin. Sosyal Psikoloji, Ege Üniversitesi, Izmir, 2013.

[8] S. M. Jex, T. W. Britt. Organizational Psychology: A Scientist-Practioner Approach, John Wiley \& Sons, New Jersey, 2008.

[9] P. Lau, Y. Y. Wong. Direct and Multiplicative Effects of Ethical Dispositions and Ethical Climates on Personal Justice Norms: A Virtue Ethics Perspective, Journal of Business Ethics, 90, 279-294, 2009.

[10] R. Burg. Deliberative Business Ethics, Journal of Business Ethics, 88, 665-683, 2010.

[11] M. Millar, C. J. Choi. Networks, Social Norms and Knowledge Sub-Network, Journal of Business Ethics, 90, 565-577, 2010. 
[12] D. M. Kivlighan Jr, D. O. Cole. The Group’s Absence Norm and Commitment to the Group as Predictors of Group Member Absence in the Next Session: An Actor-Partner Analysis, Journal of Counseling Psychology, 59(1), 41-49, 2012.

[13] S. Tauber, K. Sassenberg. The Impact of Identification on Adherence to Group Norms in Team Sports: Who Is Going the Extra Mile?, Group Dynamics: Theory, Research, and Practice, 16(4), 231-240, 2012.

[14] S. H. Heap, D. Zizzo. The Value of Groups, American Economic Review, 99(1), 295-323, 2009.

[15] S. Valentine, L. Godkin, G. M. Fleichman, R. Kidwell. Corporate Ethical Values, Group Creativity, Job Satisfaction and Turnover Intention: The Impact of Work Context on Work Response, Journal of Business Ethics, 98(3), 353-372, 2011.

[16] B. L. Bonner, S. D. Sillito. Leveraging Member Knowledge in Group Decision-Making: Expertise, Extroversion, and Feedback, Group Dynamics: Theory, Research, and Practice, Vol. 15, No. 3, 233-245, 2011.

[17] C. K. W. De Dreu, B. A. Nijstad, M. N. Bechtoldt, M. Baas. Group Creativity and Innovation: A Motivated Information Processing Perspective, Psychology of Aesthetics, Creativity, and the Arts, 5(1), 81- 89, 2011.

[18] J. W. Slocum., D. Hellriegel. Principles of Organizational Behavior, 12th edition, China: Cengage Learning, 345-350, 2009.

[19] F. Kalay, S. Oğrak. Free Riders in the Organizational Environment, Report of Management and Organization Conference, Izmir, 2012.

[20] F. P. Morgeson, D. S. DeRue, D. E. P. Karam. Leadership in teams: A functional approach to understanding leadership structures and processes, Journal of Management, 36, 5-39, 2010.

[21] T. Seppala, J. Lipponen. Leader Fairness and Employees' Trust in Coworkers: The Moderating Role of Leader Group Prototypicality, Group Dynamics: Theory, Research, and Practice, 16(1), 35-49, 2012.

[22] D. M. Kivlighan, K. London, J. R. Miles. Are Two Heads Better Than One? The Relationship Between Number of Group Leaders and Group Members, and Group Climate and Group Member Benefit From Therapy, Group Dynamics: Theory, Research, and Practice, 16(1), 1-13, 2012.
[23] D. Man, S. S. Lam. The effects of job complexity and autonomy on cohesiveness in collectivistic and individualistic work groups: a cross-cultural analysis, Journal of Organizational Behavior, 24, 979-1001, 2003.

[24] Y. Chen, X. S. Li. Group Identity and Social Preferences, American Economic Review 2, 99(1), 431-457, 2009.

[25] A. K. Newheiser, J. F. Dovidio. Individual differences and intergroup bias: Divergent Dynamics associated with prejudice and stereotyping, Personality and Individual Differences, Yale University, 70-74, 2012.

[26] S. McPherson, D.P. Craig. Intergroup and Interindividual Resource Competition Escalating Into Conflict: The Elimination Option, Group Dynamics: Theory, Research, and Practice, 15(4), 285-296, 2011.

[27] A. Klep, B. Wisse, H. Van Der Flier. Interactive affective sharing versus non-interactive affective sharing in workgroups: Comparative effects of group effect on work group performance and dynamics, European Journal of Social Psychology, 41, 312-323, 2011.

[28] K. Yee Ng, L. Van Dyne. Antecedents and Performance Consequences of Helping Behavior in Work Groups, Group and Organization Management, 30(5), 514- 540, 2005.

[29] R. E. Kidwell, S. R. Valentine. Positive Group Context, Work Attitudes, and Organizational Misbehavior: The Case of Witholding Job Effort, Journal of Business Ethics, 86(1), 15-28, 2009

[30] A. Kleingeld, H. van Mierlo, L. Arends. The Effect of Goal Setting on Group Performance: A Meta-Analysis, Journal of Applied Psychology, 96(6), 1289-1304, 2011.

[31] N. J. Choi. Collective Dynamics of Citizenship Behaviour: What Group Characteristics Promote Group-Level Helping?, Journal of Management Studies, 46(8), 2009.

[32] W. M. Davies. (2009).Group work as a form of assessment: common problems and recommended solutions, High Educ., 58:563-584, Springer Science -Business Media B.V. , Online available from http://www.itl.usyd.edu.au/assessme ntresources/pdf/Link10.pdf

[33] L. Goette, D. Huffman, S. Meier. The Impact of Social Ties on Group Interactions: Evidence from Minimal Groups and Randomly Assigned Real Groups, American Economic Journal:Microeconomics, 4 (1), 2012. 